\title{
The Feasibility Analysis of Modularization Teaching in advanced Mathematics Teaching in Vocational Colleges

\author{
Xiaoyi Luo
}

Hebei Vocational College of Politics and Law, Shijiazhuang, 050061, China

Keywords: Modularization teaching, Vocational college, Advanced mathematics teaching, Application, Feasibility

Abstract. In recent years educational problems especially the advanced mathematics teaching in China's vocational colleges are paid with more attention. Therefore in the practical teaching process of the advanced mathematics, positively introduce in modularization teaching will be the irresistible trend of the vocational colleges reforms. Meanwhile, modularization teaching is also the combination of personality education, innovation education and quality oriented education. Aimed at the practical features of the mathematics courses in the vocational colleges and the practical need of the students, modularization teaching has its positive function. Thus students' learning competence and interest of mathematics can be improved and teachers' classroom teaching quality and efficiency can be guaranteed.

\section{Introduction}

When it comes to modularization teaching, in the beginning it was a training model applied by international labor organizations. This model is similar with the combination of the building blocks. It is widely applied in the skill training of vocational teachings and professional teachings. Thus introducing in modularization teaching to the advanced mathematics teaching in vocational colleges can effectively obscure the systematicness of mathematics. Then the applicability of mathematics will be brought into full play.

The feasibility analysis of modularization teaching in advanced mathematics teaching in vocational colleges

\section{The need of modern vocational teaching system construction}

According to the regulations of the policies of China's educational reforms, by the year of 2020, the economy development pattern will be on speaking terms with industrial structure, and the thought of lifelong education will be demonstrated. The construction of modern vocational education system will be realized. And subject of mathematics is one of the most important public elementary courses in vocational colleges. Therefore the formation must be firm enough and modules can be more flexible. In the same time secondary vocational colleges should be perfectly linked to vocational colleges so that students of different levels can transit naturally. ${ }^{[1]}$

Therefore the application of modularization teaching in advanced mathematics teaching in vocational colleges has a practical meaning.

\section{The requirement of two college entrance examination models}

China' s college entrance examination model will be reformed soon. It will be divided into two models. That is to say skilled talents and academic talents will be examined respectively. The mathematical knowledge and competence which the two types of talents need to hold are different. Skill talents need to know mathematics better which means profoundly hold the basic module of mathematics. Meanwhile academic talents need to know how to use mathematics better, and make themselves familiar with the application module and improving module of mathematics. Therefore, reforming the traditional type of advanced mathematics and positively introducing in modularization teaching have its feasibility. 


\section{The status and analysis of the advanced mathematics in vocational colleges}

\section{The sources of the students in vocational colleges are complicated with different levels}

At this stage, the popularization of China' s higher education is improving. The scales of vocational colleges are getting bigger. This phenomenon gives the vocational colleges with diversified student sources in which there are not only graduates from normal high schools, but also graduates from secondary vocational schools. Graduates from normal high schools are divided into students majored in science and students majored in art. So the different types of students in vocational schools are the main reasons of the level differences of the student sources. Among those differences, the difference of mathematical foundation is the most important which impedes the development of the advanced mathematics in vocational colleges.

The content of the courses of advanced mathematics is too much, while the class hour is too little.

In the content of the courses in vocational colleges, as a basic subject, advanced mathematics is the required subject. But in terms of the practical features of practical education in vocational colleges, the class hour of its theoretical class is not enough. To a certain degree the importance of the basic is neglected. Professional courses even take up the time for basic elementary courses. Therefore the students neglect the importance of elementary courses. The elementary causes are in a tight corner. So to accomplish all the contents of course in a short time is impossible. However the teachers take the teaching method of duck stuffing to accomplish the teaching task in time. The students in turn go into a weary condition.

The professional standard of the mathematics teachers in vocational colleges is not high enough

Most mathematics teachers teaching in vocational colleges are graduated from teachers' schools. Though perfect themselves in the mathematics theoretical knowledge, they cannot be skilled teachers. Without the qualification of "Double qualified teacher" , they don't know the professional knowledge on computer and machinery and do not have enough practical experience. Therefore they cannot blend professional contents effectively during the practical teaching process of advanced mathematics and can not lay a solid formation for the later study of the students. ${ }^{[2]}$

From the situation above, we can find out that modularization teaching in advanced mathematics in vocational colleges can effectively demonstrate the unique features of mathematics subject and the features of vocational college education itself

\section{An overview of the modularization teaching in advanced mathematics in vocational colleges}

Modularization teaching concentrates on the training of skills in site. It is widely applied in many developing countries. Aimed at the practical need of the students for mathematics, the traditional contents of teaching are recombined and reselected so that the students can finish all the studying contents with high efficiency.

The modularization teaching in vocational colleges is mainly divided into two models: lengthways and crosswise. Lengthways means to decompose all the contents of the course, clarify the teaching goal, method, difficulty, and content of each module aiming at different modules, then chooses the module according to professional practical need. Crosswise is to decompose the content of each module for the second time. And divide it into three levels which include leading in, explanation and applied modules. Same modules have same contents, but their professional levels are different. So the settings of the leading in module and the applied module are quite different.

\section{The main contents of modularization teaching in advanced mathematics in vocational colleges}

According to the requirement of different majors in vocational colleges for mathematics, the teaching content of advanced mathematics is divided into three modules: universal, exclusive use and 
optional. ${ }^{[3]}$ The division for the three models can better fulfill the practical professional requirement. The universal module is divided into three parts: 1 , function and limit. This part includes notion and calculation of limit and explanation for the successional of function. 2. The differential for unary function. Its main content is the conception of differential coefficient and the calculation as well as differential and its application. 3. Integral calculus of unary function. It includes conceptions of definite integral and indefinite integral, the nature and the calculation. The contents included in the modules above can be applied to any majors in vocational colleges. The content of the course is about eighteen class hours and should be taught in the first term.

Exclusive use module can be divided into four parts:1. It includes integral transmission, elementary linear algebra, infinite series and differential equation. All these contents can be applied in the development of electronic commercial software and every major in computer department. The class hour should be controlled in forty eight class hours. 2. Infinite series, ordinary differential equation and Laplace transformation are mainly applied in the electric automatization, communication technology, electronic information engineering. The class hour is also forty eight class hours. 3. Elementary linear algebra, probability and preliminary mathematical statistics are widely applied in the automatic engineering and electronic engineering. The class hour is also forty eight class hours. 4. Basic graph theory. It is often applied in the management department and foreign language department. The class hour is about forty eight class hours. The contents of exclusive use module are arranged in the second term.

The contents of optional module mainly include mathematical modeling, mathematical leading edge information, mathematical experiment and mathematical history. And the status and the expectations of the subjects are also included. The needed class hours are to be confirmed. The requirement has to be made according to different majors and different student levels then penetrate these requirements in the optional courses and related knowledge lectures. It gives mathematics teaching with pertinence and also demonstrates the main features of advanced mathematics in the vocational colleges of applicability, fundamentality and instrumental.

\section{The specific applications of modularization teaching in the mathematics teaching in vocational colleges}

\section{Setting principles of course teaching}

First, professionalism. The setting for courses must take the occupation need of students into consideration and take the occupation' s practicability as a standard. From the point of view of solving problems, make use of practical cases to teach to demonstrate the significance of mathematics in practical life.

Second, specialization. The setting for courses must take the occupation need into consideration. The accountant must agree with the training objective which could help students to study mathematical knowledge with practicability in a short time.

Third, capacity. The setting for courses must take the developing need of students into consideration. It must emphasize the students as the key point, and pays attention to the training for the occupation transfer ability, occupation changing ability, and lifelong learning ability.

\section{Course system construction}

After the overall study of the setting principles of course teaching, the construction of the court system of advanced mathematics in vocational colleges has to consider the future development of students and the need of its own majors. The modules of the course system are: basis, improvement and application. ${ }^{[4]}$ The module of the basis is the required course. It is the basis of mathematical calculus that students should perfect themselves in.

The improving module is mainly optional course which can be applied to the students who take part in self study examination and upgrade students from junior college. The application module is the practical application of mathematics in students' majors which can solve students' confusions in a certain degree and raise the study interest of students. The form of this model is also optional course. 
Modularization teaching has an important function in raising the interest of studying mathematics and set a solid foundation of the further studies of mathematics.

\section{The teaching arrangement after the improvement of courses}

At this stage, the credit system has not been completely realized in the mathematics teaching in vocational colleges. There's no professional difference and most of the students are taught with advanced mathematics in the first term. The class hour is four class hours per week. As freshmen, students haven't got rid of the mood of vacation so they often get tired with the class of two class hours. Therefore we can positively introduce modularization teaching in the arrangement of courses. Teach at once the mathematics in the same time. In the first term it is required course, in the second it turns to optional course. Thus student can choose mathematics modules according to his own interest and his own developing direction. And math teachers can choose the correct teaching contents according to their own teaching characteristics.

\section{The mating resource needed by modularization teaching in advanced mathematics in vocational colleges}

\section{The perfection of teacher' s levels and teaching contents}

To better realize the goal of advanced mathematics courses, we must value the important status of teachers. The quality and capacity of mathematics teachers have direct influence on the implementation effect of modularization teaching. Therefore, aiming at different module contents of advanced mathematics, we need to choose different mathematics teachers and establish the corresponding project teams. Aiming at the bases module, we need to choose experienced mathematics teachers. For the teaching in the mathematics software module, we can choose teachers with good basic knowledge of computer technology. Then the relationship of mutual help can be formed and it will effectively connect the theory and the practical teaching of advanced mathematics. Furthermore, aiming at the mathematical lecture project, we can choose teachers with abundant knowledge and work on mathematics studies. Especially for the mathematical confusions, we must select teachers who study on the mathematical modeling.

\section{The perfection of mathematical textbooks and teaching methods}

To adapt modularization teaching, mathematical textbooks also need corresponding perfection and improvement. By transforming and combining different mathematic models, the flexible characteristics of textbooks in vocational colleges can be realized. Though the relationships among different models are not too close, each module can establish teaching unit independently. Meanwhile, the combination of theory and practice of each module must be realized. Furthermore the form of the textbook of modularization teaching must be active and electronic which can effectively break through the barriers between the practical classroom and the theoretical classroom and adapter the phenomenon of the various sources of students then continuously fulfill the need for lifetime study of students.

\section{The perfection of professional assessment and innovation}

To take modularization teaching in advanced mathematics, we need The perfection of assessment forms. Different models need different forms of assessment. The basis module could make use of open type paperless question bank, and the proportion of student daily performance and final examination performance is $3: 7^{[5]}$.

For improving module, it is linked up with the eleven-plus and makes the application module cooperate with the innovation of the major of the students. For the combination of the practical application of mathematics subject with the student' s major, mathematical modeling is an important platform. Therefore making use of mathematical modeling, Teachers can design the topics and clarify the specific time regulations in optional courses. Meanwhile students can collect references they need, and make detailed analysis on the practical results. With the combination of requirement and practical 
situation, students can put forward detailed suggestions and eventually pass the examination by thesis. This form of examination could promote student' s competence of applying the theory in practical situations.

\section{Conclusion}

In conclusion, the modularization teaching in advanced mathematics teaching in vocational colleges has a great importance for students' later mathematics learning and professional learning. Thus the method of modularization teaching should be studied and discussed in a profound way.

\section{References}

[1] Xu Zhihong, An li. The application of Advanced mathematics modularization teaching in vocational college-Rizhao Vocational Technical Institute as an example. Journal of Qingdao Ocean seamen Training college, 2014,35(2):57-60.

[2] Wu Jianxiang, Wang yu. On the discoveries on the advanced mathematics teaching mode reform in vocational colleges. Chinese education and technology innovation Herald, 2011(14):18-18.

[3] Cai Jin. On the refine teaching of advanced mathematics in vocational colleges. Jilin College of education, 2013, 29(6):80-81.

[4] Wang Jiaofeng, Huang Bin. The studies on the MES in advanced mathematics in vocational colleges. Education and science magazine, 2013(19):66-66,68.

[5] Huang Yingling. Studies on the modularization teaching in advanced mathematics. Higher education studies, 2010(1):89-91. 